\title{
RISK FOR TUBERCULOSIS DURING TREATMENT WITH BIOLOGICAL THERAPY: IS IT TIME FOR REVIEWING SCREENING PROTOCOL? - RESULTS FROM BRAZILIAN REGISTRY OF BIOLOGICAL THERAPIES IN RHEUMATIC DISEASES (BIOBADABRASIL)
}

A Medeiros Ribeiro (BIOBADABRASIL, Sao Paulo, SP, Brasil), M Bredemeier (BIOBADABRASIL, Sao Paulo, RS, Brasil), V Valim (BIOBADABRASIL, Sao Paulo, ES, Brasil), M Pinheiro (BIOBADABRASIL, Sao Paulo, SP, Brasil), C Macieira (BIOBADABRASIL, Sao Paulo, SP, Brasil), A Duarte (BIOBADABRASIL, Sao Paulo, SP, Brasil), B Stadler (BIOBADABRASIL, Sao Paulo, SP, Brasil), R Ranza (BIOBADABRASIL, Sao Paulo, SP, Brasil), M Bertolo (BIOBADABRASIL, Sao Paulo, SP, Brasil), J Miranda (BIOBADABRASIL, Sao Paulo, SP, Brasil), C Brenol (BIOBADABRASIL, Sao Paulo, SP, Brasil), G Castro (BIOBADABRASIL, Sao Paulo, SP, Brasil), V Fernandes (BIOBADABRASIL, Sao Paulo, SP, Brasil), D Titton (BIOBADABRASIL, Sao Paulo, SP, Brasil), F Sauma (BIOBADABRASIL, Sao Paulo, SP, Brasil), I Pereira (BIOBADABRASIL, Sao Paulo, SP, Brasil), R Botelho (BIOBADABRASIL, Sao Paulo, SP, Brasil), H Carvalho (BIOBADABRASIL, Sao Paulo, SP, Brasil), A Hayata (BIOBADABRASIL, Sao Paulo, SP, Brasil), P Louzada (BIOBADABRASIL, Sao Paulo, SP, Brasil), A Ranzolin (BIOBADABRASIL, Sao Paulo, SP, Brasil), S Studart (BIOBADABRASIL, Sao Paulo, SP, Brasil), G Castelar (BIOBADABRASIL, Sao Paulo, SP, Brasil), A Kakehasi (BIOBADABRASIL, Sao Paulo, SP, Brasil), W Bianchi (BIOBADABRASIL, Sao Paulo, SP, Brasil), A Acayaba (BIOBADABRASIL, Sao Paulo, SP, Brasil), I Silveira (BIOBADABRASIL, Sao Paulo, SP, Brasil), H Resende (BIOBADABRASIL, Sao Paulo, SP, Brasil), J Amaral (BIOBADABRASIL, Sao Paulo, SP, Brasil), L Rocha (BIOBADABRASIL, Sao Paulo, SP, Brasil), M Gazzeta (BIOBADABRASIL, Sao Paulo, SP, Brasil), L Carvalho (BIOBADABRASIL, Sao Paulo, SP, Brasil), S Schowalski (BIOBADABRASIL, Sao Paulo, SP, Brasil), D Feldman (BIOBADABRASIL, Sao Paulo, SP, Brasil), I Laurindo (BIOBADABRASIL, Sao Paulo, SP, Brasil), J Provenza (BIOBADABRASIL, Sao Paulo, SP, Brasil)

\section{BACKGROUND}

Brazil is accountable for $33 \%$ of the tuberculosis(TB) burden in Americas and the occurrence of tuberculosis in patients with rheumatic diseases under biological therapy is a recurrent concern. The objective was to assess incident TB among patients with rheumatic disease in use of biological therapy in Brazil.

\section{MATERIALS AND METHODS}

BiobadaBrasil is a multicentric prospective cohort of patients with rheumatic diseases who started the first biologic or a synthetic disease modifying anti-rheumatic drug(DMARD). This analysis included patients with rheumatoid arthritis(RA), psoriatic arthritis(PsA), and ankylosing spondylitis(AS) (Jan,2009 to Aug,2018) followed for one or multiple courses of treatment until censoring or incident TB. The primary outcome was the incidence of tuberculosis in any organ site. The history of previous tuberculosis, or latent tuberculosis infection (LTBI)diagnosis(exposure to tuberculosis, chest X-ray, or positive TST) and treatment (prophylactic isoniazid) were evaluated before each course of treatment. Multivariate Cox proportional hazards models (with DMARDs included as time-varying covariates) were used to estimate hazard ratios (HR) and 95\% confidence intervals (CI); analyses were performed with the Survival package of $R$.

\section{RESULTS}

Sample: 2,858 patients (female $=70,2 \%$; $\mathrm{RA}=72 \%, \mathrm{AS}=20 \%, \mathrm{PsA}=8 \%$ ), corresponding to 16,401 patientsyear. A total of $31(1.1 \%)$ patients developed tuberculosis during treatment, most of them ( $n=24 ; 77 \%)$ on monoclonal antibodies TNF-inhibitors (mAbTNFi). The median (interquartile range) exposure to the current DMARD course was 11.1 (5.9-20) months. Cases occured both early and lately during treatment courses.TB patients did not significantly differ from others regarding disease duration, sex or age. Almost 
half ( $n=14 ; 45 \%)$ of TB patients did not present evidence of previous exposure or any screening positive test for TB; 9 (29\%) TB patients had received adequate LTBI treatment (isoniazid) recently or in the past. Furthermore, $8(26 \%)$ had incomplete/inconsistent screening. Overall incidence of TB was 1.9/1000 patients/year, and was not significantly different among the diseases (1.63 for RA, 2.06, for AS, and 3.79/1000/year for PsA). In univariate analysis, exposure to anti-TNF monoclonal antibodies (HR 3.1, $95 \% \mathrm{Cl}$ 1.18-8.15, $\mathrm{P}=0.02$ ) and presence of any marker of previous contact with TB (positive history of TB, known contact with TB, positive TST, or abnormal chest X-ray: HR $4.2(2.1-8.5, p<0.001)$ were positively associated with the risk of TB. Including simultaneously these variables in the Cox model, they were independent risk factor for TB $(p<0.05)$.

\section{CONCLUSION}

MAb-TNFi and previous exposure/diagnosis of TB are independent risk factors for developing TB in Brazil, that occurred both early and lately during treatment courses, suggesting LTBI screening failures, treatment non-adherence and re-exposure. 